\title{
Immunoblot analysis of antigens associated with Haemophilus ducreyi using serum from immunised rabbits
}

\author{
JAMES M SAUNDERS AND JAMES D FOLDS
}

From the Department of Microbiology and Immunology, School of Medicine, University of North Carolina, Chapel Hill, North Carolina, United States of America

SUMMARY Sodium dodecyl sulphate polyacrylamide gel electrophoresis and immunoblotting were used to characterise isolates of Haemophilus ducreyi. Isolates of $H$ ducrey $i$ were heterogeneous in protein composition, but isolates from single outbreaks appeared similar both in protein profiles and antigenic analysis. Rabbits immunised with $H$ ducreyi responded with a vigorous humoral immune response in which multiple antigenic polypeptides were detected. The most prominent antigens had molecular masses of $67,42,22 \cdot 5$, and 20 kilodaltons.

\section{Introduction}

Chancroid is a sexually transmitted disease of the genitalia resulting from Haemophilus ducreyi infection. The disease manifests itself clinically as an inflammatory pustule or papule, which rapidly progresses into a painful purulent ulcer if untreated. One or more secondary ulcers often develop through autoinocculation.

Throughout the world, chancroid poses an appreciable public health problem, possibly outranking syphilis in prevalence. ${ }^{1}$ The disease is most predominant in tropical and undeveloped countries and is not yet considered to be a common sexually transmitted disease (STD) in the United States of America. The Centers for Disease Control (CDC), however, estimates that about 1000 cases are reported yearly, ${ }^{2}$ and clustered outbreaks have been reported in Canada, ${ }^{3}$ Europe, ${ }^{4}$ and the USA. ${ }^{5}$ Many workers believe that the estimates established do not truly reflect the incidence of the disease, as an appreciable proportion of cases of ulcerative chancroid are often misdiagnosed as other STDs, such as syphilis or genital herpes. ${ }^{6}{ }^{7}$ Mixed infections are also common, further confounding the differential diagnosis of chancroid.'

Address for reprints: Dr J D Folds, Department of Microbiology and Immunology, School of Medicine, University of North Carolina, Chapel Hill, North Carolina 27514, USA

Accepted for publication 24 February 1986
The diagnosis of chancroid is currently based on coupling the clinical features with a laborious process of eliminating other potential causative agents. ${ }^{8}$ Identification of $\boldsymbol{H}$ ducreyi by culture and staining techniques is usually only moderately successful ${ }^{1}$ because of the organism's complex nutritional requirements and general fragility. Newer culture media and more refined techniques, however, have improved the reliability of isoolation of $\boldsymbol{H}$ ducreyi. . $^{9-12}$

In recent efforts to identify some of the immunological characteristics of $\boldsymbol{H}$ ducreyi, the protein profiles of numerous isolates of the bacterium were analysed by sodium dodecyl sulphate polyacrylamide gel electrophoresis (SDS-PAGE). ${ }^{13}$ This technique proved to be useful in subtyping the isolates according to the patterns of proteins in the range of 24 to 50 kilodaltons molecular mass. In addition, monoclonal antibodies have been developed that are known to react with antigens in at least 12 isolates of $H$ ducreyi. ${ }^{14}$ Clearly, a comprehensive understanding of the antigenic nature of $\boldsymbol{H}$ ducreyi would not only help to define the bacterium and its epidemiological character more accurately, but may also lead to improved diagnostic immunological tests. In the study published here we combined gel electrophoresis with immunoblotting techniques to examine the antigenic similarities of $10 \mathrm{H}$ ducreyi isolates and three representative members of the genus Haemophilus. We also examined the antigenic reactivities of serum from normal and immunised rabbits to the proteins present in each isolate. 


\section{Materials and methods}

\section{BACTERIA}

$H$ influenzae type b and non-typable (NT), $H$ parainfluenzae, and $H$ ducreyi ATCC 27722 isolates were obtained from the Clinical Microbiology and Immunology Laboratories of North Carolina Memorial Hospital, Chapel Hill, North Carolina. $H$ ducrey $i$ isolates $\mathrm{K}-1, \mathrm{~K}-147, \mathrm{~K}-152,1-255,4124$, 870,914 , and 1-277 were provided by the CDC and represented outbreaks in Atlanta, Georgia, (K-1 to K-152) and Orange County, California, (1-255 to 1-277). Isolates 35000 and 54198, provided by $\mathrm{Dr}$ Allan Ronald of the University of Manitoba, had originated from an outbreak in Winnipeg, ${ }^{3}$ and isolate CIP542, from the Pasteur Institute, served as one of the reference strains. All Haemophilus isolates were cultured on chocolate or blood agar plates and incubated in candle jars with a humidified carbon dioxide atmosphere. The strains of $\boldsymbol{H}$ ducrey $i$ were incubated at $34^{\circ} \mathrm{C}$ for four days, whereas those of $H$ influenzae and $H$ parainfluenzae were incubated at $37^{\circ} \mathrm{C}$ for two days. The organisms were harvested by flooding the surface of the agar with phosphate buffered saline (PBS) containing Tween (a sorbitan polyoxyalkalene derivative) and collecting the colonies with sterile swabs. The cells were washed twice in PBS, aliquotted, and stored at $-20^{\circ} \mathrm{C}$.

\section{ANTIBODIES}

Experimental rabbit antisera, which served as probes against potentially antigenic proteins of Haemophilus, were obtained by intradermal inoculation of three rabbits with three different $\boldsymbol{H}$ ducrey $\boldsymbol{i}$ isolates, ATCC 27722 , $\mathrm{K}-147$, and $\mathrm{K}-1$. In this procedure, the rabbits received injections of whole organisms suspended in an equal volume of complete Freund's adjuvant on alternate days for one week. Three weeks later, the animals received booster injections of the organism in incomplete Freund's adjuvant. Blood samples were taken before immunisations and at weekly intervals after the booster injection. The antisera from each blood sample collected after the booster injection were pooled according to the isolate injected. Two of the serum samples taken before inoculation served as controls.

\section{SDS-PAGE AND IMMUNOBLOTTING ANALYSIS}

The protein content of each Haemophilus isolate was analysed by polyacrylamide gel electrophoresis (PAGE) as described by Laemmli. ${ }^{15}$ In this procedure, sample proteins were dissolved by heating them to $100^{\circ} \mathrm{C}$ for five minutes in a buffer containing $2 \%$ sodium dodecyl sulphate (SDS), $5 \%$ betamercaptoethanol, $10 \%$ glycerol, and $0.01 \%$ bromphenol blue in a $62.5 \mathrm{mmol} / 1$ trometamol (TRIS) base (pH 6.8). To remove residual cellular debris, all dissolved samples were subsequently centrifuged at $8000 \times \mathrm{g}$ for 15 seconds. The supernatants (35 $\mu \mathrm{g}$ protein) were loaded on to gradient $8-20 \%$ polyacrylamide gels and electrophoresed at $5 \mathrm{~mA}$ until the dye front had been electrophoresed off the gel for one hour. The gels were stained in Coomassie blue, destained in acid-alcohol, and photographs were taken.

Immunoblotting techniques ${ }^{16}$ were used to assess the antigenic reactivity between the proteins in the isolates and the sera of normal rabbits and rabbits immunised with three different $\boldsymbol{H}$ ducreyi isolates. Once the dissolved proteins had been fractionated as described, they were electrophoresed by a perpendicular current at $195 \mathrm{~mA}$ for one hour and at $50 \mathrm{~mA}$ for one hour on to $0.2 \mu \mathrm{m}$ nitrocellulose filters. The transfer was made in a buffer containing $25 \mathrm{mmol} / \mathrm{l}$ TRIS, $192 \mathrm{mmol} / 1$ glycine, and 20\% methanol. After the transfer, the filters were incubated for one hour in $5 \%$ bovine serum albumin-TRIS saline azide (BSATSA) to block any remaining protein binding sites on the filters. The filters were then incubated in 1:100 dilutions of the normal rabbit sera (control) and the immunised rabbit sera (probe) for about 16 hours. The blots were subsequently washed for one hour in four changes of TSA and incubated for two hours in staphylococcal protein A labelled with iodine-125 $\left({ }^{125} \mathrm{I}\right)$ at $1-2 \times 10^{6}$ counts per minute $(\mathrm{cpm})$. The labelled nitrocellulose filters were washed extensively in TSA to remove unbound label, air dried, and autoradiographed. All washes and incubations were performed at room temperature.

\section{Results}

PROTEIN PROFILES OF GENUS HAEMOPHILUS ISOLATES

The SDS-PAGE polypeptide profiles of the representative genus members examined in this study are shown in figure 1 . Though some similarities could be found, the protein banding patterns of the bacteria were generally dissimilar.

\section{PROTEIN PROFILES OF H DUCREYI ISOLATES}

The proteins found in various $\boldsymbol{H}$ ducrey $i$ isolates were subjected to SDS-PAGE and Coomassie blue staining. At least 25 distinct polypeptides were shown, some of which were common to numerous isolates (fig 2). The molecular masses of the proteins ranged from more than 100 kilodaltons to less than six kilodaltons, with most being between 20 and 80 kilodaltons. Though considerable heterogeneity existed among the protein profiles, at least three common protein bands occurred in all isolates. These were found to migrate at molecular masses of about 67,43 , and 39 kilodaltons. The profiles of isolates 914 and 1-277 were very similar, both having originated from an outbreak of chancroid in Orange County, California. 


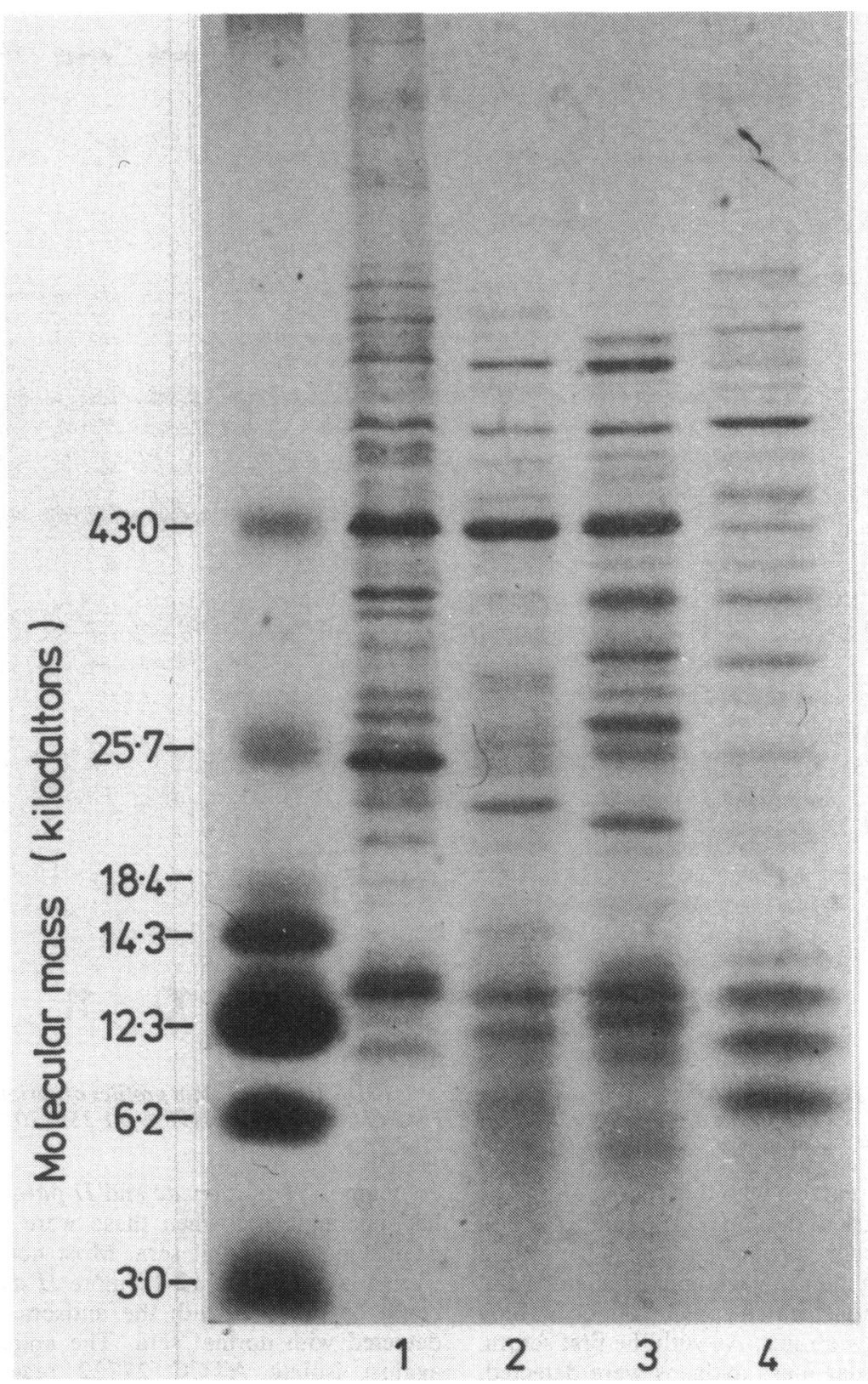

FIG 1 Sodium dodecyl sulphate polyacrylamide gel electrophoresis (SDS-PAGE) protein profiles of solubilised organisms of the genus Haemophilus: $H$ parainfluenzae (lane 1), H influenzae (NT)(2), H influenzae (type 6) (3), and $H$ ducreyi (ATCC 2722) (4). Stained with Coomassie blue dye.

HAEMOPHILUS ANTIGENS REACTIVE TO NORMAL RABBIT SERA

The proteins present in $H$ influenzae (type b and NT), $H$ parainfluenzae, and $10 \mathrm{H}$ ducreyi isolates were analysed for their non-specific antigenicity by immunoblotting them against normal rabbit sera. Each serum reacted with different sets of polypeptides that were common to many of the organisms tested (fig 3). The most intense and consistent reaction occurred between the first serum and a polypeptide detected only in the $\boldsymbol{H}$ ducrey $i$ isolates with a molecular mass of about 67 kilodaltons. Many low molecular weight 


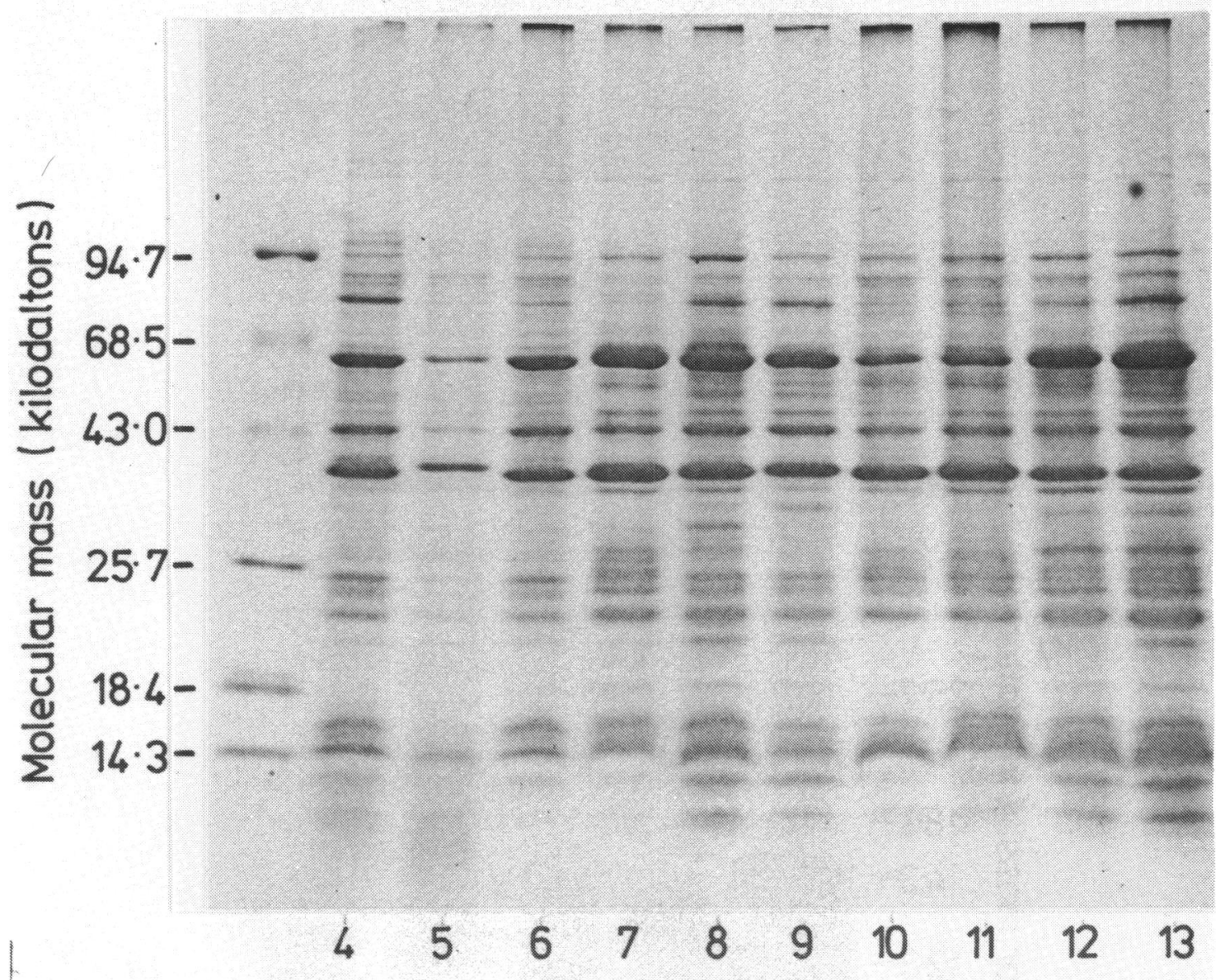

FIG 2 Sodium dodecyl sulphate polyacrylamide gel electrophoresis (SDS-PAGE) protein profiles of various Haemophilus ducreyi isolates: ATCC 27722 (lane 4), K-147 (5), K-1 (6), CIP542 (7), 35000 (8), 54198 (9), 1-255 (10), 4124(11), 914 (12), and 1-277 (13).

antigens were also reactive with this serum, and these were detected in most of the $\boldsymbol{H}$ ducreyi isolates as well as those of the other genus members. The second serum reacted most intensely with a polypeptide band at about 38 kilodaltons, which appeared to occur only within the $\boldsymbol{H}$ ducrey $\boldsymbol{i}$ strains. As with the first serum, several low molecular mass antigens were detected, but these were of lower molecular masses than those reacting with the first serum.

\section{HAEMOPHILUS ANTIGENS REACTIVE TO RABBIT} ANTISERA TO H DUCREYI

To examine further the antigenic properties of $H$ ducreyi antisera from rabbits immunised with three different isolates of $\boldsymbol{H}$ ducreyi (ATCC 27722, K-147, and $\mathrm{K}-1$ ) the antisera were immunoblotted against the proteins found in all the bacteria studied (fig 4). All the antisera reacted with four or five polypeptides common to $H$ influenzae and $H$ parainfluenzae that had not appeared when these were immunoblotted against normal rabbit sera. Most notable, however, was the finding that $12-15$ more $H$ ducrey $i$ antigens could be detected with the antisera than could be detected with normal sera. The antisera developed against isolate ATCC 27722 reacted with four antigens common to all $10 \mathrm{H}$ ducrevi isolates. These had molecular masses of about $67,42,22 \cdot 5$, and 20 kilodaltons. Antiserum against isolate K-1 detected sets of antigenic polypeptides similar to those reacting with the anti-ATCC 27722 antiserum and also detected a common antigen of about $\mathbf{4 5}$ kilodaltons. Antiserum to isolate $\mathrm{K}-147$ exhibited greater reactivity to the genus Haemophilus isolates and less reactivity to the $H$ ducreyi isolates than the other antisera tested. This antiserum also failed to react with the $\mathbf{4 2}$ kilodalton polypeptide band that had been reactive with the pre- 


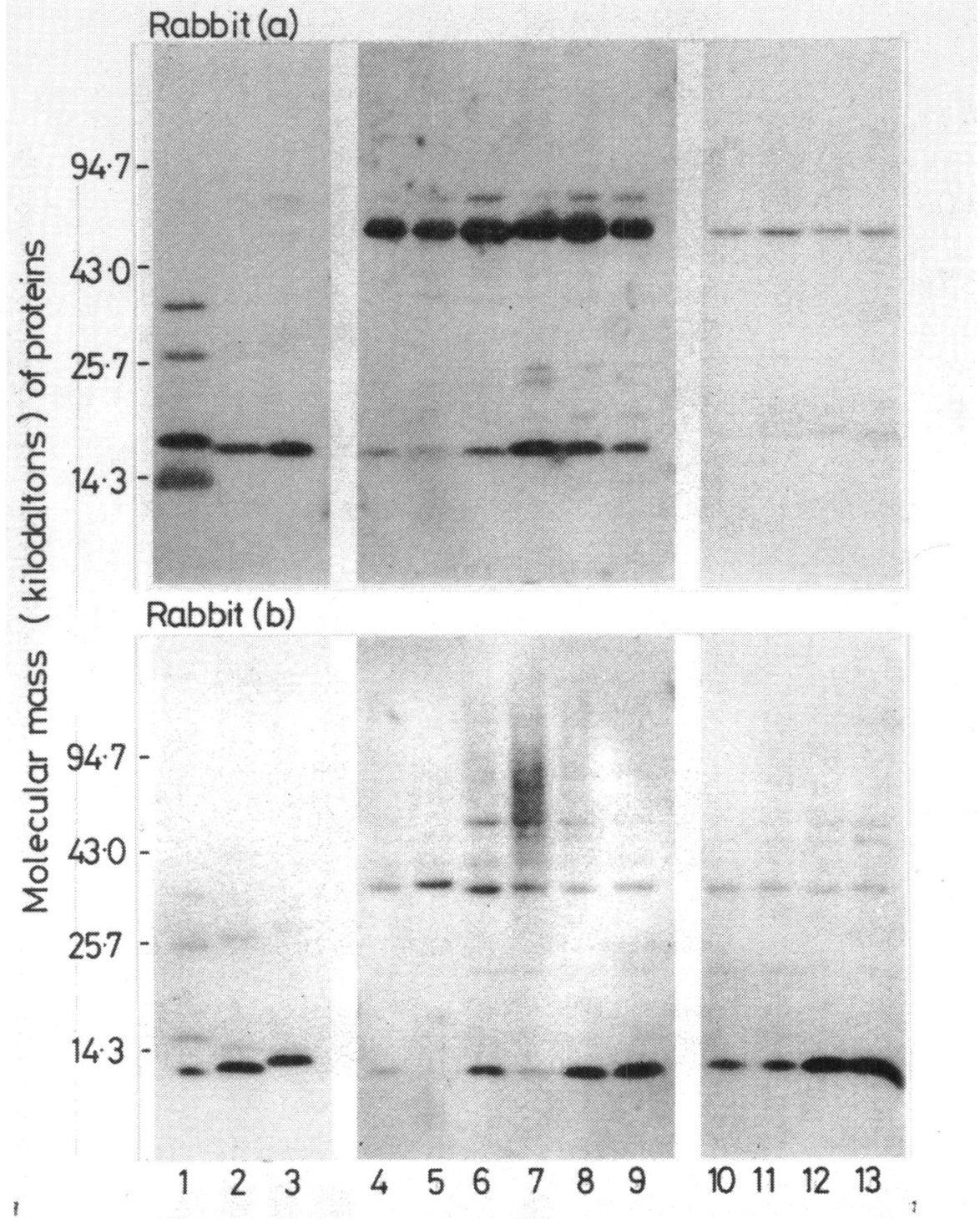

FIG 3 Autoradiograph of western blot analysis of Haemophilus polypeptides reacted with sera from two rabbits (a and b) before immunisation with $H$ ducreyi. Lane assignments as described for figs 1 and 2. Antigen-antibody reactions detected using ${ }^{125}$ I-labelled Staphylococcus aureus protein $A$.

vious antisera. Isolates 914 and 1-277 appeared to have very similar antigenic protein profiles to all three antisera.

\section{Discussion}

Odumeru et al have shown that the protein profiles of $H$ ducreyi, as assessed by SDS-PAGE, can be useful in subtyping this bacterium. ${ }^{13}$ These workers found that at least seven different subtypes could be identified based on the outer membrane protein profiles of polypeptides with molecular masses of 24 to 50 kilodaltons. They further showed that isolates from a clustered outbreak of chancroid appeared to exhibit identical protein profiles, which suggests a common origin. This point was substantiated in our study by the strong similarities found in protein profiles and antigenicities between isolates 914 and 1-277, which had originated from a single outbreak. Also in agreement with the Odumeru study were our findings that many unique antigenic polypeptides were found in the $\boldsymbol{H}$ ducrey $i$ isolates and that some antigens, such as the 40 kilodalton protein, were common to most isolates.

We used $H$ ducreyi isolates CIP542 and 35000 as 
reference strains, as their protein profiles had been analysed previously. Although our PAGE methods were somewhat different, we found that the protein profiles of these species were similar to those described previously. ${ }^{13}$ In addition, by using gradient electrophoresis gels, we detected the presence of a protein with a molecular mass of about 65 kilodaltons that was common to all the $\boldsymbol{H}$ ducreyi tested. Unlike in the previous report, however, we found that the protein profiles of $\boldsymbol{H}$ ducreyi isolates were quite different from those of $\boldsymbol{H}$ influenzae and $\boldsymbol{H}$ parainfluenzae isolates. Such inconsistencies may originate in variations between protein solubilisation and gel electrophoresis methods that were used.

Normal rabbit sera reacted with antigens found to be in common in most of the micro-organisms tested in this immunoblotting analysis. The first serum detected an intensely reactive band at 67 kilodaltons that was common only to the $H$ ducreyi isolates and a band of low molecular mass antigens also common to other genus members. The second normal serum reacted with a different set of Haemophilus antigens that did not include the 67 kilodaltons protein seen previously. These disparities most probably reflected the presence of non-specific antibodies in normal rabbit sera that were capable of cross reacting with antigens found in other members of the genus Haemophilus.

Immunisation of rabbits with whole $H$ ducreyi isolates elicited profound immunological responses, which caused sharp increases in the number of antigenic polypeptides that could be detected when reacted against the rabbit antisera. Whereas the antisera cross reacted with a variety of antigens in each of the non- $H$ ducreyi isolates, similar patterns of antigenic bands were found in the $H$ ducrey $i$ isolates. Highly reactive polypeptides were detected with molecular masses of about $67,22 \cdot 5$, and 20 kilodaltons in all the $\boldsymbol{H}$ ducreyi tested. Two of the antisera additionally reacted with a polypeptide at 42 kilodaltons and one with a polypeptide at 45 kilodaltons. It is interesting to note that identical inoculation conditions for organisms with related origins elicited variable immune responses between animals. For example, as can be seen in fig 4, antiserum from the animal immunised against isolate $\mathrm{K}-147$ detected fewer antigenic polypeptides in the $H$ ducreyi isolates than did antiserum against isolate $\mathrm{K}$ 1 , even though they had both originated from a clustered outbreak in Atlanta.

This study was performed to elucidate some of the immunological characteristics of an important pathogenic organism, $\boldsymbol{H}$ ducreyi, which is often clinically misinterpreted in cases of ulcerative STD. Earlier studies by Ito $^{17}$ and Dienst ${ }^{18}$ indicated that cellular immunity to this bacterium develops during active infection in man or after intradermal inoculation in rabbits. Others have found that complement fixing antibodies may be detected in the serum of patients with the disease. ${ }^{19}$ An indirect immunofluorescence technique $^{20}$ and monoclonal antibodies to $H$ ducreyi antigen $s^{14}$ have recently been developed, and these may soon become powerful tools in defining the antigenic properties of this micro-organism. In this study, we have shown that rabbits appear to carry nonspecific antibodies capable of reacting with various Haemophilus antigens and that rabbits immunised against $H$ ducreyi develop a vigorous immunological response, which results in the production of $\mathrm{IgG}$ antibodies that recognise a wide range of Haemophilus antigens, especially those found in $H$ ducreyi. Furthermore, some of these antigens appear to be uniquely associated with $H$ ducreyi.

We thank Mr Randy Thresher for editorial assistance on this manuscript.

\section{References}

1. Hafiz S, Kinghorn G, McEntegart G. Haemophilus ducreyi and chancroid. In: Easmon C, Jelijaszewicz J, eds. Medical microbiology. Vol 4. London: Academic Press, 1984:14370.

2. United States Public Health Service. Sexually transmitted disease statistics, 1983. Washington DC: US Department of Health and Human Services, Feb, 1985; issue no. 133.

3. Hammond G, Slutchuk M, Scatliff J, Sherman E, Wilk J, Ronald A. Epidemiologic, clinical laboratory and therapeutic features of an urban outbreak of chancroid in North America. Rev Infect Dis 1980;2:867-9.

4. Kinghorn GR, Hafiz S, McEntegart MG. Pathogenic microbial flora of genital ulcers in Sheffield with particular reference to herpes simplex virus and Haemophilus ducreyi. British Journal of Veneral Diseases 1982;58:377-80.

5. Centers for Disease Control. Chancroid California. MMWR 1982;31:173-5.

6. Ronald A, Plummer F. Chancroid and Haemophilus ducreyi. Ann Intern Med 1985;102:705-7.

7. Chapel T, Brown W, Jeffries C, Stewart J. How reliable is the morphologic diagnosis of penile ulcerations? Sex Transm Dis 1977; 4:150-2.

8. Becker $T$, Larsen S. Chancroid: not just another tropical disease. Diagnostic Medicine 1984;7:32-3.

9. Hammond G, Lian C, Wilt J, Ronald A. Comparison of specimen collection and laboratory techniques for isolation of Hemophilus ducreyi. J Clin Microbiol 1978;7:39-43.

10. Kinghorn GR, Hafiz S, McEntegart MG. Modified haemincontaining medium for isolation of Haemophilus ducreyi. Lancet 1982;i:393-4.

11. Oberhofer T, Back A. Isolation and cultivation of Hemophilus ducreyi. J Clin Microbiol 1982;15:625-9.

12. Sottnek F, Biddle J, Kraus W, Weaver R, Stewart J. Isolation and identification of Hemophilus ducrey $i$ in a clinical study. $J$ Clin Microbiol 1979;12:170-9.

13. Odumeru J, Ronald A, Albritton W. Characterization of cell proteins of Hemophilus ducreyi by polyacrylamide gel electrophoresis. J Infect Dis 1983;148:710-4.

14. Hansen E, Loftus T. Monoclonal antibodies reactive with all strains of Hemophilus ducreyi. Infect Immun 1984;44:196-8.

15. Laemmli V. Cleavage of structural proteins during the assembly of the head of bacteriophage T4. Nature 1970;227:680-5.

16. Saunders JM, Folds JD. Humoral response of the mouse to Treponema pallidum. Genitourin Med 1985;61:221-9. 
17. Ito $\mathbf{T}$. Klinische und bakteriologisch-serologische studien uber ulcus molle und Ducreysche Streptobazillen. Archiv für Dermatologie und Syphilis 1913;116:341-9.

18. Dienst R. Virulence and antigenicity of Hemophilus ducreyi. American Journal of Syphilis, Gonorrhea and Venereal Diseases 1948;32:289-302.
19. Reymann F. Specificity of skin tests in lymphogranuloma venereum and chancroid. Acta Derm Venereol (Stockh) 1951;37:257-71.

20. Denys GA, Chapel TA, Jefferies CD. An indirect fluorescent antibody technique for Hemophilus ducreyi. Health Laboratory Science 1978;15:128-32. 